\title{
INSCRIBING BEHAVIOUR IN INFORMATION INFRASTRUCTURE STANDARDS
}

\author{
Ole Hanseth \\ Norwegian Computing Center \\ Eric Monteiro \\ Norwegian University of Science and Technology
}

\begin{abstract}
Abstact-This paper focuses on the processes producing the standards which make up the technical back-bone of an information infrastructure. These standards are neither ready-made nor neutral. They are currently being developed, and they 'inscribe' behaviour in complex and non-transparent ways. We explore how this takes place, identifying by whom, where and how inscriptions are made. Our principal aim is to uncover the socio-technical complexity of establishing an information infrastructure, a complexity which so far has been severely underestimated by those involved. By studying the process of aligning and linking one inscription to other inscriptions, we also hope to learn more about the strength of inscriptions, that is, the degree to which an inscription actually succeeds in enforcing a desired behaviour. The empirical basis of our analysis is a case-study of standardization processes of health information infrastructure from Norway. (O) 1997 Elsevier Science Ltd. All rights reserved.
\end{abstract}

Keywords: Information infrastructure, Inscriptions, Standardization process, Actor-network theory, Health care

\section{INTRODUCTION}

The technical basis for an information infrastructure is the standards which regulate the communicative patterns. These standards are currently negotiated, developed and shaped through complex social processes. They embody inter-organizational changes in the specific way they regulate the communicative patterns. This implies that the organization of the standardization activities, usually through a variety of formal standardization bodies, deserves closer scrutiny because it is an important-but neglected-element of the social process through which organizational networks are transformed.

Establishing a working information infrastructure is a highly complex socio-technical task which at least includes: designing a large collection of communication standards, testing and adapting these to a wide range of different use situations, and ensuring that the standards are developed according to the bureacratic procedures of international standardization bodies. The challenges involved in making standards have so far been significantly underestimated and benefits exaggerated, generating a considerable level of frustration (Graham, LobetMaris \& Charles, 1996; UN, 1996; Williams, 1997).

Our principal aim is to uncover more of the socio-technical problems of establishing an information infrastructure. We are particularly concerned with how any given element of an 
information infrastructure constrains others, that is, how it 'inscribes' a certain pattern use. Some of these inscriptions are in technical components, notably the different kinds and levels of communication standards. Such inscriptions (attempt to) pre-determine the pattern of use of the standards. Other inscriptions are of a highly non-technical nature, for instance, the bureacratic organization and procedures for working out international standards. The different bureacratic arrangements, for instance, inscribe distinct opportunities and mechanisms for user input. Both the technical and the non-technical inscriptions need to be considered together when establishing an information infrastructure. By studying the process of aligning and linking inscriptions, we also hope to learn more about their strengths, i.e. the degree to which an inscription actually succeeds in enforcing a desired behaviour.

The remainder of the paper is organised as follows. The theoretical framework used, actor-network theory, borrowed from the field of science and technology studies, is outlined in Section 2. Section 3 deals with the development of general purpose information infrastructures. It delineates the notion of information infrastructure, sketches the organization of the international standardization processes, defines health information infrastructure and briefly reviews relevant research on standardization. Section 4 considers methodological issues relevant to our study. Given the fact that the object of our study is rather big (often global) and currently in-the-making, our study has made a number of pragmatically motivated approximations. Section 5 presents the case of standardization of health information infrastructure focusing on transmission of lab orders and reports together with prescriptions. Lab communication evolves at an international level, prescriptions largely on a national one. Section 6.1 discusses the picture of information infrastructure standardization which emerges through our study as well as possible implications for actor network theory. Section 7 offers a few concluding remarks.

\section{INSCRIBING ORGANIZATIONAL BEHAVIOUR IN TECHNOLOGY}

The relationship between technology and society may be conceptualized in many ways. Two extreme end points of a continuum of alternatives are, on the one hand, technological determinism holding that the development of technology follows its own logic and that the technology determine its use (Winner, 1977) and, on the other hand, social reductionism or constructionism (Woolgar, 1991a), (which comes close to technological somnabulism (Pfaffenberger, 1988; Winner, 1977) holding that society and its actors develop the technology it 'wants' and use it as they want, implying that technology in itself plays no role. A series of Braverman inspired studies appeared in the late 70 s and early 80 s biased towards a technological determinist position arguing that the use of IT was but the latest way of promoting management's interests regarding deskilling and control of labour (Sandberg, 1979). Later, a number of studies belonging close to the social constructivist end of the continuum were produced which focused on diversity of use among a group of users and displaying use far beyond what was anticipated by the designers (Henderson \& Kyng, 1991; Woolgar, 1991b).

Today, the majority of scholars in the field adhere to an intermediate position somewhere between the two extreme positions outlined above. The majority of accounts end up with the very important, but all too crude, insight that "information technology has both restricting and enabling implications" (Orlikowski \& Robey, 1991, p. 154). This insight-that IT enables and constrains-is reached using a rich variety of theoretical frameworks including structuration theory (Orlikowski \& Robey, 1991), phenomenology (Boland \& Greenberg, 1992), 
hermeneutics (Klein \& Lyytinen, 1992) or Habermas' theory of communicative action (Gustavsen \& Engelstad, 1990).

Hence, there can hardly be said to be a lack of suggestions for suitable theoretical frameworks (Kling, 1991; Monteiro \& Hanseth, 1995). We will, however, introduce yet another one, actor network theory, which we believe will bring us one step further towards a more detailed understanding of the relationships between information technology and its use (Akrich, 1992; Akrich \& Latour, 1992; Callon, 1991, 1994; Latour, 1987). This choice is motivated by the way actor network theory, especially in the minimalistic variant we employ, offers a language for describing the many small, concrete technical and non-technical mechanisms which go into the negotiations of standards. Actor network theory accordingly goes a long way in describing which and how actions are enabled and constrained.

Actor network theory views society as a completely interwoven socio-technical web. It consists of a highly heterogeneous network of actors, institutional arrangements, textual descriptions, work practices and technical artefacts. In line with its semiotic origin, actor network theory is granting all entities of such a heterogeneous network the same explanatory status because "semiotics is the study of order building ( . . .) and may be applied to settings, machines, bodies, and programming languages as well as text ( . . .) [because] semiotics is not limited to signs" (Akrich \& Latour, 1992, p. 259). It might perhaps seem a radical move to grant artefacts the same explanatory status as human actors: does not this reduce human actors to mere objects and social science to natural science? We intend to bracket this rather dogmatic issue. Interested readers should consult (Callon \& Latour, 1992; Collins \& Yearley, 1992). For our purposes, what is important is that this move has the potential for increasing the level of detail and precision. More specifically, allowing oneself not to distinguish a priori between social and technical elements of a socio-technical web encourages a detailed description of the concrete mechanisms at work which glue the network together-without being distracted by the means, technical or non-technical, of actually achieving this.

Two concepts from actor network theory are of particular relevance for our inquiry: inscription (Akrich, 1992; Akrich \& Latour, 1992) and translation (Callon, 1991, 1994; Latour, 1987). The notion of inscription refers to the way technical artefacts embody patterns of use: "Technical objects thus simultaneously embody and measure a set of relations between heterogeneous elements" (Akrich, 1992, p. 205). Balancing the tight-rope between, on the one hand, an objectivistic stance where artefacts determine the use and, on the other hand, a subjectivistic stance holding that an artefact is always interpreted and appropriated flexibly, the notion of an inscription may be used to describe how concrete anticipations and restrictions of future patterns of use are involved in the development and use of a technology. Akrich (1992, p. 208, emphasis added) explains the notion of inscription in the following way:

"Designers thus define actors with specific tastes, competences, motives, aspirations, political prejudices, and the rest, and they assume that morality, technology, science, and economy will evolve in particular ways. A large part of the work of innovators is that of 'inscribing' this vision of (or prediction about) the world in the technical content of the new object. ( . . .) The technical realization of the innovator's beliefs about the relationship between an object and its surrounding actors is thus an attempt to predetermine the settings that users are asked to imagine (...)." 
Stability and social order, according to actor network theory, are continually negotiated as a social process of aligning interests. As actors from the outset have a diverse set of interests, stability rests crucially on the ability to translate, that is, re-present or appropriate, others' interests to one's own. In other words, with a translation one and the same interest or anticipation may be presented in two different ways thereby mobilising broader support. A translation presupposes a medium or a "material into which it is inscribed", that is, translations are "embodied in texts, machines, bodily skills [which] become their support, their more or less faithful executive" (Callon, 1991, p. 143).

The designer works out a scenario of the system under design together with the interaction between the users and the system. This scenario is inscribed into the system. The inscription includes programs of action for the users, and it delegates roles and competencies to the users as well as the components of the system (Latour, 1991). By inscribing programs of actions into a piece of technology, the technology becomes an actor ${ }^{1}$ by imposing its inscribed program of action on its users.

The inscribed patterns of use may not succeed because the actual use deviates from it. Rather than following its assigned program of action, a user may use the system in an unanticipated way, she may follow an anti-program (Latour, 1991). When studying the use of technical artefacts one necessarily shifts back and forth "between the designer's projected user and the real user" in order to describe this dynamic negotiation process (Akrich, 1992, p. 209). Some technologies inscribe weak/flexible programs of action while others inscribe strong/inflexible programs. Examples of the former are tools, the hammer being a classic example, and the assembly line of Chaplin's "Modern times" a standard illustration of the latter.

Inscriptions are given a concrete content because they represent interests inscribed into a material. The flexibility of inscriptions vary, some structure the pattern of use strongly, others weakly. The strength of inscriptions, whether they must be followed or can be avoided, depends on the irreversibility of the actor-network they are inscribed into. It is never possible to know beforehand, but by studying the sequence of attempted inscriptions we learn more about exactly how and which inscriptions were needed to achieve a given aim. To exemplify, consider what it takes to establish a specific work routine. One could, for instance, try to inscribe the routine into required skills through training. Or, if this inscription was too weak, one could inscribe the routine into a textual description in the form of manuals. Or, if this still is too weak, one could inscribe the work routines by supporting them by an information system. Hence, through a process of translation, one and the same work routine may be attempted inscribed into different materials. By adding and linking these inscriptions they accumulate strength.

Latour (1991) provides an illuminating illustration of this aspect of actor network theory. It is an example intended for pedagogic purposes. Hotels, from the point of view of management, want to ensure that the guests leave their keys at the front desk when leaving. The way this objective may be accomplished, according to actor network theory, is to inscribe the desired pattern of behaviour into an actor-network. The question then becomes how to inscribe it and into what. This is impossible to know for sure before hand, so management had to make a sequence of trials to test the strength of different inscriptions. In Latour's story, management first tried to inscribe it into an artifact in the form of a sign behind the

\footnotetext{
'Or 'actant' as would be the more precise term in actor network theory (Akrich \& Latour, 1992).
} 
counter requesting all guests to return the key when leaving. This inscription, however, was not strong enough. Then they tried having a manual door-keeper-with the same result. Management then inscribed it into a key with a metal knob of some weight. By stepwise increasing the weight of the knob, the desired behaviour was finally achieved. Hence, through a succession of translations, the hotels' interest were finally inscribed into a network strong enough to impose the desired behaviour on the guests.

In the analysis in Section 6.3 we discuss various extensions of the minimalistic version of actor network theory presented here. Still, there are four aspects of the notions of inscription and translation which are particularly relevant and which we emphasize in our study: (i) the identification of explicit anticipations (or scenarios) of use held by the various actors during design (that is, standardization), (ii) how these anticipations are translated and inscribed into the standards (that is, the materials of the inscriptions), (iii) who inscribes them and (iv) the strength of these inscriptions, that is, the effort it takes to oppose or work around them.

\section{STANDARDIZATION AND THE BUILDING OF INFORMATION INFRASTRUCTURE}

\subsection{Information infrastructure}

The notion of information infrastructure as well as basically synonymous terms like infobahn, information or electronic highways, is elusive. It is currently receiving a considerable amount of attention from academics, politicians and the public. It is fairly safe to expect that future information infrastructure will consist of an elaboration, extension and combination of existing computer networks with associated services (Smarr \& Catlett, 1992). It is likely to consist of an inter-connected collection of computer networks, but with a heterogeneity, size and complexity extending beyond what exists today. New services will be established, for instance, by developing today's more experimentally motivated services like video-ondemand and electronic publishing. These new services subsequently accumulate pressure for new development of the information infrastructure to accommodate them.

There exist today a number of embryonic manifestations of the information infrastructures. Internet will perhaps by most of us be considered a global information infrastructure providing general purpose services that may be used as they are or as a basis for building more specific, application dependent services. For many years, we have had application specific networks. Services provided include flight booking and bank networks supporting automatic teller machines and other economic transactions. Electronic Data Interchange (EDI), that is, electronic transmission of form-like business and trade information, is an illustration of an existing technology related to information infrastructure (Graham, Spinardi, Williams \& Webster, 1995; Webster, 1995).

\subsection{Standards and standardization processes}

One normally distinguishes between de facto, de jure and formal standardization (Schmidt \& Werle, 1992). De facto standardization is characterized by its reliance on market forces; there are no regulating, institutional arrangements influencing the process. De jure standardization denotes the situation where standards are approved and given a law-like status by an institution authorised for this. The third type of process, formal standardization, is most relevant in the present context.

Information infrastructures, like many other kinds of large technical systems (Hughes, 1987), are standardized by formal, quasi-democratic, international standardization bodies 
(Lehr, 1992). These standardization bodies have to follow predefined procedures and rules regulating the status, organization and process of developing standards. In recognition of the limits of both market forces and hierarchical control, formal standardization is a key strategy for developing an information infrastructure (OECD, 1991). Internationally, there are currently three important institutions responsible for formal stanadardization of general purpose information infrastructure:

- the International Standardization Organization (and its European branch, CEN);

- EDIFACT ${ }^{2}$ within the United Nations;

- Internet ${ }^{3}$.

These three institutions organize the process of standardization quite differently along several important dimensions including: the way participation in the process is regulated, how voting procedures are organized, the requirements proposed standards have to meet at different stages in the process, the manner information about ongoing standardization is made public, and the bureacratic arrangements of how work on one, specific standard is aligned with other efforts. For a more detailed description of these differences, consult (Graham et al., 1995; Hanseth, Monteiro \& Hatling, 1996; Lehr, 1992; RFC, 1994).

De facto standards are often developed by industrial consortia or vendors. Examples of such standards are the W3 consortium currently developing a new version of the HTML format for WorldWideWeb, IBM's SNA protocol and the Health Level $7^{4}$ standard for health care communication.

\subsection{Information infrastructure for health care}

Health information infrastructure is use of an information infrastructure within the health care sector. It has evolved over a period of 10 years and takes different shapes over time. Its two main types are transmission of form-like information and (possibly real-time) multimedia information. Illustrations of the former include: lab orders and reports exchanged between general practitioners, hospitals or labs and (other) labs; admission and discharge letters between general practitioners, specialists, and hospitals; prescriptions from general practitioners to pharmacies; exchange of non-medical information like ordering of equipment and food and invoices from hospitals and general practitioners to health insurance offices for reimbursement. Illustrations of the latter type include: telemedicine services, that is, computer based services which usually include real time multi-media conferencing systems supporting a physician requesting advise from another physician at another institution; access to data bases and Web servers containing medical information; and PACS (picture achieve systems for X-rays) systems. In this paper, we focus on the former type, i.e. transmission of form-like information.

The various forms of information exchange are overlapping and interconnected. The same

\footnotetext{
${ }^{2}$ EDIFACT is an abbreviation for Electronic Data Interchange (EDI) for Administration, Commerce and Transport.

${ }^{3}$ The term Internet may have three different meanings which sometimes need to be distinguished. Internet may denote: (i) the existing, physical data network, (ii) the collection of Internet Standards or (iii) the bureacratic organization of, and procedures for, how standardization is to take place. In the present context, Internet is used in the sense of (iii).

${ }^{4}$ Health Level 7 is a standard worked out by an ad-hoc formation of a group of smaller vendors in the United States, later on being affiliated to American National Standards Institute, ANSI (see url http://www.mcis.duke.edu/ standards/HL7/hl7.htm).
} 
piece of information may be exchanged as part of different transactions, for instance, by transmission of a digital X-ray image either using a multi-media conference system or attached in an e-mail. Furthermore, any organizational unit may engage in transactions with several other units. A lab, for instance, may communicate with a number of general practitioners, other labs, and other hospital wards. This is what distinguish such systems from stand-alone applications and turn them into infrastructure.

The development of health information infrastructure standards-not to mention their implementation in products and adoption by user organizations-has been slow. Based on personal experience, it seems that the more formal the standardization process is, the slower the adoption becomes. Industrial consortia seem so far to be most successful. As, to the best of our knowledge, there does not exist any systematic evaluation, this is difficult to document. But studies in other sectors than health care exist. The evaluation of the European Union's program for diffusion of EDI in trade, the TEDIS programme, lend support to the view that formal standardization is incredible slow-design as well as diffusion (Graham et al., 1996). An evaluation of EDIFACT on behalf of the United Nations concludes similarly (UN, 1996).

\subsection{Research on standardization}

Our approach to the study of standardization resembles those applied by Marc Berg, Geoffrey Bowker, Leigh Star and Stefan Timmermans (Bowker \& Star, 1994; Bowker, Timmermans \& Star, 1995; Star \& Ruhleder, 1994; Timmermans \& Berg, 1997). In their studies of classification schemes and infrastructures Bowker and Star identify a number of issues which are closely related to those we are focusing on. In a study of the evolution of the classification of deseases maintained by the World Health Organization, they illustrate how coding and classification-essential tasks in the establishment of an information infrastructure-is anything but neutral. Interests are inscribed into coding schemes (Bowker \& Star, 1994). Bowker et al. (1995) study how some aspects of work is made more visible than other by inscribing them into a classification scheme. Star and Ruhleder (1996) discuss key characteristics of infrastructure based on a study of the introduction and use of an information infrastructure.

Other studies of the standardization process of information infrastructure tend to focus issues rather different from ours and those mentioned above. These include the economical significance of standards (David, 1987; OECD, 1991), technical challenges (Rose, 1992), the use of information infrastructures (Ciborra, 1992), the political nature of standardization bodies (Webster, 1995) or cultural differences (Trauth, Derksen \& Mevissen, 1993). The predominant view on information infrastructure standardization is that it is straightforward. An exception to this is (Williams, 1997). Standardization is commonly portrayed either as (i) a fairly unproblematic application of mainstream techniques for solving the technical difficulties of software engineering or (ii) it is simply glossed over or taken as given (Ciborra, 1992; David, 1987; OECD, 1991). Those involved in the design of information infrastructure have so far been very close to (i). These studies shed little light on the socio-technical complexity of establishing an information infrastructure.

Within the field of social studies of technology, there are some contributions relevant to a study of information infrastructure standardization. Some focus on conceptual issues, for instance, the work by Fujimura (1992) on standardizing procedures and interpretations across geographical distances. Others explore empirically how universal standards are appropriated to local contexts (Berg, 1997) or how the interplay between stability and change is played out (Hanseth et al., 1996). 
As we see it, standards and standardization are key elements and processes in the realization of the envisioned information infrastructures. This is a task raising a wide range of new challenges, challenges we will not be able to deal with properly without extensive research-to which we try to give a modest contribution through this paper. It seems as if this view is shared by a growing number of scholars, and some research is appearing, for instance analysis of standardization strategies (Kahin \& Abbate, 1995), including drawing lessons from the earlier standardization efforts like Internet (Abbate, 1994) and X/Open.

\section{METHODOLOGICAL ISSUES}

Studying the development of information infrastructures is not straightforward. There are at least two reasons for this which have immediate methodological implications worth reflecting upon.

First, the size of an information infrastructure makes detailed studies of all elements practically prohibitive. Internet, for instance, consists of an estimated 10 million nodes with an unknown number of users, more than 200 standards which have, and still are, extended and modified over a period of 25 years within a large, geographically dispersed organization where also a number of vendors (Sun, IBM, Microsoft), commercial interests (MasterCard, Visa) and consortia (W3) attempt to exercise influence. This implies that the notion of an actor in connection with information infrastructure standardization is a fairly general one in the sense that it is sometimes an individual, a group, an organization or a governmental institution. An actor may also be a technological artifact—small and simple or a large system or network like Internet or EDIFACT. Actor network theory has a scalable notion of an actor as Callon and Latour (1981, p. 286) explain: "[M]acro-actors are micro-actors sitting on top of many (leaky) black boxes". In other words, actor network theory does not distinguish between a macro- and micro-actor because opening one (macro) black-box, there is always a new actor-network. It is not a question of principle but of convenience, then, which blackboxes are opened and which are not. To account for information infrastructure standardization within reasonable space limits, it is necessary to rely on such a scalable notion of an actor. A systematic, comprehensive empirical study is prohibitive. In our study, we have opened some, but far from every, black-box. Several black-boxes have been left unopened for different reasons: some due to constraints on writing space, some due to lack of data access and some due to constraints on research resources. It might be desirable to have opened more black-boxes than we have done. We believe, however, we have opened enough to be able to present a reasonable picture of standardization. Our empirical evidence is drawn from standardization of EDI messages within the health care sector in Norway. A method of historical reconstruction from reports, minutes and standards documents together with semi- and unstructured interview has been employed, partly based on (Pedersen, 1996). One of the authors was for a period of 3 years engaged in the development of the standards by two of the companies involved (Telenor and Fearnley Data). Our account of the case has been presented, discussed and validated with one of the key actors (KITH, Norwegian: Kompetansesenteret for IT i Helsesektoren A/S).

Second, the fact that information infrastructures are currently being developed and established implies that there is only limited material on about the practical experience with which solutions 'survive' and which 'die', i.e. which inscriptions are actually strong enough to enforce the desired pattern of use. Hence, we are caught in a dilemma. On the one hand, the pressure for grounding an empirical study suggests that we need to await the situation, 
let the dust settle before inquiring closer. On the other hand, we are strongly motivated by a desire to engage in the ongoing process of developing information infrastructures in order to influence them (Hanseth et al., 1996).

Our approach is pragmatic. We present an emerging picture of information infrastructure standardization based on the empirical material at hand but adjusting it as more experience with information infrastructures is acquired. Although all the EDI standards we consider in "5. Inscriptions in standards" are not in ordinary, widespread use, there is some practical experience with using them. They exhibit a number of salient features of information infrastructure standardization.

\section{INSCR IPTIONS IN STANDARDS}

We now turn to a more detailed exploration of inscriptions in standards by focusing on one case, the development of standards and infrastructures in Norway for information exchange between different institutions like general practitioner offices, hospitals, laboratories, pharmacies and social insurance offices. The work in Norway was, and still is, closely linked to international standardization. Accordingly, our case can be read as an example of a more general situation as well.

The process of inscribing programs of action into standards is illustrated by focusing on the standardization of lab orders and reports together with drug prescriptions. This process unfolds as a sequence of translations where new translations are negotiated among the actors involved in the standardization process and the strength of inscriptions are tested. During these negotiations different actors propose and argue for different possible translation alternatives. Each alternative inscribes different programs of actions. The negotiations produce winners and losers, as translation alternatives reflect interests differently.

Standardization of lab communication was quickly and strongly aligned with activities at an international level while the prescription efforts were basically situated in Norway and only weakly aligned with international ones. Our case is presented basically by unwrapping the process as it unfolds historically over the years from the late 80 s up till today. We pay attention to the four aspects of inscriptions outlined in Section 2, especially illustrating the wide range of technical and non-technical materials for inscriptions. One technical material we study closely is the overall standardization model which was adopted, namely EDIFACT. We outline the translation process leading to this decision as well as its role in the subsequent translations. We also illustrate inscriptions into non-technical materials like standardization bodies, the organization of the standardization activities and the procedures for standardization.

\subsection{Constructing the need for open standards}

There were several, alternative standardization and information infrastructure development strategies, or models, promoted originally. These models are all more or less based on deepseated convictions about how technology development takes place. They inscribe quite different spheres of authoritative competence and steps to proceed in the design. The range of technically feasible standardization models was practically unlimited. This implied that deciding on one model was less a question of technical superiority of any one model and more a question of who should be allowed to function as a gatekeeper in defining the problem.

The development of electronic information exchange between health care institutions in Norway started when a private lab, Dr Fürst's Medisinske Laboratorium in Oslo, developed a system for lab report transmission to general practitioners in 1987 . The system was very 
simple - the development time was only 3 weeks for one person. The interest of Dr Fürst's laboratory was simply to make profit by attracting new customers. It was based on the assumption that the system would help general practitioners save much time otherwise spent on manually registering lab reports, and that the general practitioners would find this attractive. Each general practitioner receives on average approximately 20 reports a day, which take quite some time to register manually in their medical record system.

The system proved to be a commercial success and brought them lots of general practitioners as new customers. This implied less profit for the other labs. Within a couple of years, several non-private labs (in hospitals) developed or bought systems with similar functionality in order to be competitive. Although these systems were more or less blue-prints of that of Dr Fürst's laboratory, there were differences which inscribed extra work for the vendors of electronic medical record systems for the general practitioners. This gave these vendors incentives for working out one, shared solution.

Alongside the growing number of labs adopting systems for exchange of reports, an increasing number of actors saw a wider range of applications of similar technology in other areas. These actors were represented within the health sector as well as among possible vendors of such technology. For all of them it was perceived as important that the technologies should be shared among as many groups as possible in order to reduce costs and enable interconnection of a wide range of institutions.

Telenor (the former Norwegian Telecom) had strong economical interests in promoting extensive use of tele- and data communication based services. As telecommunication technology became more integrated with IT, Telenor searched for candidates for extensive use of new and advanced services. The health sector was selected as the potentially most promising one. After an initial experiment, Telenor launched the project "Telemedicine in Northern Norway" in 1987 which was running until 1993. Although Telenor realized that the services and products developed for a specific sector like health care could never be as general as the telephone, Telenor had a strong economical incentive to make their market as large as possible. This strategy presupposes that the standards are as general as possible in order to cover as many sectors as possible.

Standardization has always been considered important within the telecommunication sector. Hence, Telenor took it for granted that the new health information infrastructure standards should be like any other telecommunication standard: 'open' and developed according to the procedures of formal standardization bodies. Telenor effectively acted as a standardization 'partisan'. Their perceived neutrality together with the investments in the telemedicine project made Telenor a very influential actor within information infrastructure standardization in Norway in the 80 s.

\subsection{Technology as ally}

As there was a general consensus - the interests were aligned - about the need for standards, the fight about what these standards should look like and how they should be developed started. This race was a seemingly neutral and technical discussion about which technology fitted the needs best. In reality, however, it was a race between different actors trying to manoeuvre themselves into key positions as 'gatekeepers' or 'obligatory passage points' (Latour, 1987). In this race, most of them chose the same generic strategy, namely to first look for the technology which seemed most beneficial for them and subsequently enrolling this technology into their own actor-network as an ally. Appealing to the symbolic character of, technology makes it possible to disguise non-technical interests as technical arguments. 
We will here present some actors and how their they were selecting technologies as allies or strategic partners.

Based on their interests in general solutions and rooted in the telecommunication tradition of international standardization, Telenor searched for international activities aiming at developing 'open' standards. The IEEE (Institute of Electrical and Electronics Engineers) P1157 committee, usually called Medix, did exactly this. This work was the result of an initiative to develop open, international standards taken at the MEDINFO conference in 1986. Medix, which was dominated by IT professionals working in large companies like Hewlard Packard and Telenor and some standardization specialists working for health care authorities, adopted the dominating approach at that time, namely that standards should be as open, general and universal as possible.

The appeal for open, universal standards inscribed in the Medix effort implied using existing OSI (Open Systems Interconnection) protocols defined by the ISO (International Standardization Organization) as underlying basis. The Medix effort adopted a standardization approach - perfectly in line with texts books in information systems development-that the development should be based on an information model being a 'true' description of the relevant part of reality, that is, the health care sector, independent of existing as well as future technology. Individual messages would be derived from the model more or less automatically.

While the focus was directed towards a comprehensive information model, lab reports were still the single most important area. However, for those involved in Medix the task of developing a Norwegian standardized lab report message had around 1990 been translated into the development of a proper object-oriented data model of the world-wide health care sector.

In addition to the information model, protocols and formats to be used had to be specified. In line with the general strategy, as few and general as possible protocols and formats should be included. Medix first focused on Open Document Architecture believing it covered all needs for document like information. However, around 1990 most agreed that EDIFACT should be included as well. The Europeans who strongest advocated EDIFACT had already established a new body, EMEDI (European Medical EDI), to promote EDIFACT in the health sector. In Norway, a driving force behind the EDIFACT movement was the 'Infrastructure programme' run by a governmental agency (Statskonsult) during 1989-92. Promoting Open Systems Interconnection standards and EDIFACT systems based on Open Systems Interconnection were key goals for the whole public sector (Statskonsult, 1992).

The Norwegian branch of Andersen Consulting, pursuing clear economical interests, was marketing a product manufactured in the United States based on the so-called Health Level 7 standard. To promote their product, they pushed Health Level 7 as a standard in Norway even though it was evident that substantial modification to make it fit a Norwegian context was required.

A second vendor, Fearnley Data, decided during 1989 to develop products supporting information exchange within the health care sector. They followed the Medix as well as the Health Level 7 activities. In early 1990, they initiated activities aiming at developing Health Level 7 based Norwegian standards. They organized a series of meetings and tried to enrol the necessary actors into a network aligned around Health Level 7 with themselves as the main gatekeeper while at the same time keeping Andersen Consulting outside the network by focusing on the amount of work required to modify their product in Norway.

In 1990 the Ministry of Health decided that standards should be developed. Responsible for this work was Gudleik Alvik. He hired a consultant, Bjørn Brevik, for doing the 
technical work. He specified a coherent set of data structures and exchange formats along the same line as that of Dr Fürst's and similar systems. The proposal was distributed for comments. The procedure followed by the ministry was the general one used for all kind of decision making concerning new rules to be followed by health care institutions. This procedure was--of course-very different from those of international telecommunication standardization. It delegated power and competencies to actors within the health care sector and not the telecommunication world. Actors from the telecommunication world mobilized and easily killed this proposal. ${ }^{5}$

KITH was established in 1991 and was delegated the responsibility for standardization by the Ministry of Health. KITH's director Bjørn Engum was the former head of Telenor's telemedicine project, and accordingly enrolled into their standardization activities. He aligned closely with Statskonsult and likewisely argued in favour of EDIFACT and OSI. As was the case with Telenor's role, key public institutions made heavy use of their perceived neutrality to advocate their interests.

Late in 1990, Fearnley Data started the development of a communication system for health care. At this time they had given up the Health Level 7 based standardization approach because EDIFACT was gaining momentum. They decided to ally with EDIFACT rather than Health Level 7. They furthermore aligned with other standardization bodies and activities, including European Medical EDI, KITH and Statskonsult. At the same time, another company (Profdoc) started the development of a product paying less attention to standardization and rather more to the experiences with existing systems.

Fearnley Data decided that their product should follow standards as far as possible. When they started, no formal decision about Norwegian or international standards had been made. However, a 'rough consensus' 6 had been reached that EDIFACT should be the basis for the exchange of structured form-like information. Accordingly, Fearnley Data considered it safe to start the implementation of an EDIFACT based solution. One of their employees, Edgar Glück (educated as a doctor, practising as a systems designer) designed a first version of a lab report message in EDIFACT based on the Health Level 7 message. Fearnley Data's strategy was to install their solutions for communication between hospital labs and general practitioners' offices in parallel with promoting the message as a proposed standard within national and international bodies. This strategy turned out to be very successful. The existence of a specified message and 'running code' had similar effects as Dr Fürst's system. As Fearnley Data had one of the very rare existing EDIFACT implementations, they were highly successful in mobilizing support for their solution. Having a concrete solution, as opposed to merely playing with paper sketches, proved to be an effective way of enrolling others. With minor changes the message was accepted by both KITH and EMEDI. EMEDI sent the message specification to the Western European EDIFACT Board as a proposal for a message being formally approved by the international EDIFACT standardization authorities. The message was quickly approved.

The alignment of interests and technologies around EDIFACT established a very powerful actor-network. EDIFACT technology in general and running EDIFACT solutions in particular were powerful actors in this alliance. Profdoc reported that it was 'impossible'

\footnotetext{
SOne of the authors was involved in this killing.

"The Internet slogan "We believe in rough consensus and running code" is indeed a precise description of their successful strategy (Hanseth et al., 1996).
} 
from 1992 to market their product as it was not based on EDIFACT and standards from the ISO. The rhetoric of 'open' standards was quite effective.

In 1990 the Commission of the European Community delegated to CEN (Comite Europeen de Normalisation, the European branch of ISO) to take responsibility for working out European standards within the health care domain in order to facilitate the economical benefits of an European inner market. CEN established a so-called technical committee (TC 251) on the 23rd of March 1990 dedicated to the development of standards within health care informatics. From this time Medix disappeared from the European scene. However, the people involved moved to CEN and CEN's work to a large extent continued along the lines of Medix.

When CEN started their work on lab reports, some proposals existed already. For this reason, they wanted to build upon one of these (CEN, 1991). They hoped the message specification worked out by Edgar Glück and approved by European Medical EDI could be proposed as a pre-standard. If so, a pre-standard for lab information could be ready already in April 1992. There was a great pressure for producing results rapidly. However, groups allied with other technologies than EDIFACT opposed this. Among these was a group consisting of just a few persons being involved in the Euclides project under the first, preparatory phase of the European Union's health care telematics programme.

The Euclides project developed a prototype of a system for lab report exchange based on their own non-standard format. After the project was completed, a company was set up in Belgium to continue the work. Being a European Union project, Euclides was well known in the European networks which the CEN work was a part of. As the CEN work was financed by the European Union, the Euclides project was perceived as more important and relevant than its size and achievements would imply. An additional, important factor was the fact that the head of the health care committee of CEN (TC 251), George De Moor, was also the manager of the Euclides project.

The Euclides group realized that they would not succeed in trying to make their format and message the only European standard. Accordingly, they made an alliance with the information modelling approach, proposing to develop an information model for the lab first, and that this model would be the primary standard. Based on this model the information could be exchanged using EDIFACT as well as other formats. This proposal was inherited from earlier Medix work, channelled to CEN by former Medix people. As more countries participated in the health care committee of CEN (TC 251) than the EMEDI group, it was decided to adopt the information modelling approach instead of modifying the EDIFACT message approved by EMEDI. This work was extended by a specification for how information should be exchanged using EDIFACT. To our knowledge, how to exchange the information using Euclides or other messages or formats have not been specified

In this process of searching for technologies as powerful allies, these were found among the general and well established ones. As EDIFACT was gaining momentum in Norway as well as Europe at this time (early 90s), EDIFACT - together with the most closely aligned standardization bodies-did occupy centre stage. The strategy first adopted by Dr Fürst's laboratory (accumulating practical experience from various contexts of use within the health care sector) was abandoned in favour of a strategy focusing on modelling techniques. This did not inscribe definite programs of action, but it did inscribe a shift in the delegation of competence about health care to competence in software engineering. This delay of gaining practical experience by aligning with international standardization bodies inscribed fewer and less direct channels for end-user input from the health care sector. 


\subsection{EDIFACT as actor}

Having reached the state where a large network was aligned around EDIFACT, we will now look more closely at the programs of action inscribed into this technology. Additionally, we consider how these inscriptions and the EDIFACT network are maintained. It is crucial to recognize that EDIFACT is not a self-contained piece of technology. It is a heterogeneous actor-network which includes: syntax for defining data structures; tools like converters and data bases for definitions of messages and message elements; a hierarchy of standardization bodies on global, regional and national levels; prevailing conceptions and established practices for how to define and implement messages; an EDIFACT industry of vendors and consultants; artifacts like manuals, documentation and educational material about EDIFACT.

The size and complexity of this network make its inscriptions strong and difficult to work against when one is enrolled into it. We will first look at programs of action related to the standardization process of EDIFACT, then we turn to patterns of use inscribed in the EDIFACT technology itself.

EDIFACT technology and the organization of EDIFACT standardization processes make it virtually impossible for users to be involved in, not to say influence, the standards. They are controlled by a group of more or less professional standardization people who work for large companies or bureaucracies. Inspired by MacKenzie's (1990) notion of the 'gyro mafia', this group may be dubbed the 'EDIFACT mafia'. This mafia's control is neither a feature of the EDIFACT format itself nor the organization of the standardization process, but it is a result of the interplay between the elements of the EDIFACT actor-network outlined above.

An unintended consequence of the complexity and non-transparency of the EDIFACT actor-network is that it inscribes barriers on end-user involvement through its requirements on the level of competence. To be involved in the standardization work, one needs to know all the rules of the game-the technological details of EDIFACT, the formal rules of the standardization bodies as well as all the informal practices. There are formal and informal rules for how a message should be composed as well as how the processes should run. An essential EDIFACT rule is that existing standardized messages and message elements should be used as far as possible when defining new ones. This implies that in order to make lab standards, one also has to be familiar with standards within virtually all other sectors as well. The effect, seemingly unanticipated, is that it preserves and professionalises the mafia's control over the process.

In addition, the tendency within EDIFACT to emphasize the technical aspects delegates an even less central role to end-users. The specification of the data format used in the first proprietary systems literally fits on one page of paper and is easily understood by those who need it. The specification of the European standardized EDIFACT message, however, is a voluminous document of 500 (!) pages (CEN, 1994a, b). Where this message is used, the information exchanged is almost exactly the same as when using the old systems (CEN, 1992, 1993a, b; KITH, 1994)! The bias in lab communication standardization towards the technical and general issues at the expense of the practical is shared by other EDIFACT efforts as documented by the evaluation of the European Union's programme on diffusion of EDI in the trade sector, the TEDIS programme (Graham et al., 1996). In this sense, the bureacratic and procedural arrangements of EDIFACT inscribe few and only indirect opportunities for user influence.

Compared to modern programming language constructs, the EDIFACT syntax is quite 
primitive. These shortcomings inscribe centralised control and barriers to flexible appropriation to local contexts of use (Hanseth, Thoresen \& Winner, 1993). The non-transparency of the overall EDIFACT actor-network tends to make these inscriptions invisible and hence unanticipated.

Technically speaking, the EDIFACT syntax lacks constructs for subtyping (or inheritance), pointers and recursive data structures. The ability to subtype would come in very handy when defining standards covering different geographical areas and different disciplines. Subtyping provides a mechanism for defining a standard as a collection of modular building blocks. The lab messages have been defined in order to serve the purpose of a large number of labs (for instance, clinical-chemical labs, micro-biological labs and X-ray labs). In addition, there are geographical differences. Using EDIFACT, a number of different subsets or specializations of the message have to be worked out. As support for subtyping is lacking, the only way of enabling this is to define a European message covering all local variations as optional elements. Local specializations are then defined by specifying which of the optional elements are mandatory and which ones should not be used. With subtyping, local modifications would be contained within one module, leaving all other unchanged. Some other aspects of EDIFACT will be demonstrated and discussed in section 6 .

EDIFACT inscribes certain patterns of use. This is partly inscribed in the broadly established view that EDIFACT is mimicking today's physical exchange of paper forms, orders and invoices being paradigm examples. This view is also translated into the choice of communication carrier for exchanging EDIFACT messages, i.e. using e-mail as standardized by the ISO. Using e-mail implies that the receivers get information when the senders want to provide them and not when receivers themselves want it. For clinical-chemical laboratories, for instance, the results will be sent to the ordering general practitioner when the ordered tests are completely analysed, or at predefined intermediate points in the analysis process. This inscribes a behaviour which blocks what is possible with some existing, non-standardized systems. The Fürst laboratory in Norway and its customers use a system where the general practitioners at any time may access the results produced in the analysis processes up to that very moment in time. This function will not be provided by the standardized, e-mail based solution. Other EDIFACT inscriptions will be touched upon in later sections.

\subsection{Enrolling the general practitioners}

Labs have an economical interest in receiving orders electronically as they could save a lot of labour intensive registration work. The ordering general practitioners, however, do not enjoy the same kind of immediate and tangible advantage. In order to enrol the general practitioners, electronic transmission of lab communication needs to translate the interests of the general practitioners' into the system. So far, this has not been resolved. Several attempts are being made, some of which will be presented here.

A crucial aspect of ordering tests is to ensure that an order and the specimen it belongs to are not mixed with others. A procedure followed by some general practitioners and labs today is the following: Each copy of the paper order is given a unique number. This number is printed on two different places on the form, including one adhesive label that is to be removed from the order and glued on the specimen container. In addition, the paper order is connected to the specimen container. Reproducing this level of security in the scenario when the order is transmitted electronically has turned out to be rather challenging, and will certainly include the design of specific technological as well as organizational arrangements. The design of a solution for lab orders invariably involves the alignment of the complete 
heterogeneous network of the collection of associated work routines as well as computer systems.

A possible solution that has been discussed is using a collection of label producing machines (bar code printers), label reading machines, manual routines and new computer applications. Each time an order is filled out, a barcode label will be printed by the general practitioner's system and subsequently glued to the specimen container. The unique number represented by the barcode is also a part of the specimen identifier in the order message. When the lab receives a specimen, a machine must read the barcode on the label and ensure that the specimen is attached to its proper order (already received electronically by the lab). The standardized message will inscribe the working routines for instance, the kind of information necessary for carrying out the control routines depends on how these routines are defined. However, as the general practitioners do not have any obvious advantages from electronic ordering, it is reasonable to expect that they are not interested in investing in barcode printers and other technological components this proposal demands.

During 1996, two different solutions have been tested out in Norway, each involving one lab and just a few general practitioners. One of them is based on what is called two dimensional bar codes. The complete order information is represented by a two dimensional barcode and printed on a label glued on the specimen container. The other solution is based on electronic transmission of the order using the standard European EDIFACT message, while a paper form is also printed and sent together with the specimen as in the current practice.

When orders are sent electronically, some new possibilities and advantages for the general practitioners as well are possible. One idea, which Dr Fürst's lab wants to implement, is to take advantage of the possibility for ordering new tests of a specimen when the results of those ordered first are available. Usually a general practitioner orders several tests of the same specimen. Which combination of tests that are most interesting depends on the results of the analysis. Accordingly, it would be useful to order some tests, study the results and then decide on which additional tests that are relevant. When both orders and results are transmitted electronically, this possibility may become reality. It is, however, easier to implement this functionality using the on-line connection in Dr Fürst's laboratory original, nonstandardized solution. Such new services might be attractive to general practitioners and enable labs to enrol them into the networks necessary for making electronic ordering work. However, the programs of action inscribed into the standardized solutions based on EDIFACT and the ISO e-mail standards make it impossible to implement such services within that framework. Dr Fürst's laboratory is interested in experimenting with communication technology to develop new or improved services for the general practitioners and their patients. They have so far judged EDIFACT technology too complex and inflexible and intends to wait until simpler and more flexible technology is accepted ${ }^{7}$. Web technology might fulfil the technical requirements for such technology, but this remains to be seen.

\subsection{Aligning interests}

The idea of electronic transmission of prescriptions grew out of a feasibility study as part of Statskonsult's Infrastructure programme. This area was also identified as an interesting one in Telenor's Telemedicine project (Section 5.1) (Statskonsult, 1992). Establishing an

\footnotetext{
${ }^{7}$ Interview with IT director Sten Tore Fiskerud, Feb. 1996.
} 
infrastructure for electronic exchange of prescriptions requires the alignment of a wide range of different interests, including general practitioners, pharmacies, patients, the government and social insurance offices.

Unlike lab messages, there has up till now not been much done on an international level regarding electronic prescriptions. The effort in Norway we report on accordingly represents an early attempt to standardize prescription messages. As will become evident further below, the institutional arrangements of the standardization process which link national and international efforts tightly, have resulted in a proposed, international standard for prescriptions heavily influenced by the Norwegian project.

The overall objectives of Statskonsult's Infrastructure programme was to improved productivity, service quality, and cost containment in the public sector. Spendings on pharmaceuticals are high, and accordingly an important area for cost containment. In addition, the health care authorities wanted enhanced control concerning the use of drugs by patients as well as prescription practices of physicians concerning habit-forming drugs.

The interests of the pharmacies were primarily improved logistics and eliminating unnecessary retyping of information (Statskonsult, 1992). By integrating the system receiving prescriptions with the existing system for electronic ordering of drugs, the pharmacies would essentially have a just-in-time production scheme established. In addition, the pharmacies viewed it as an opportunity for improving the quality of service to their customers. A survey had documented that as much of $80 \%$ of their customers were favourable to reducing waiting time at the pharmacies as a result of electronic transmission of prescriptions (Pedersen, 1996).

As part of the Infrastructure programme KITH worked out a preliminary specification of an EDIFACT message for prescriptions (KITH, 1992). The pharmacies also wanted to include information about so-called bonus arrangements (Norwegian: frikort) into this message. Certain categories of patients get (up till 100\%) bonus on their drugs. This bonus is subsidized by the health insurance authorities on the basis of special reports from the pharmacies.

The interests of general practitioners in the project had different sources. Electronic prescriptions would eliminate retyping a lot of information which already was stored in the medical record system. It would also greatly support the reports the general practitioners send to the health insurance authorities, some of them being the basis for their payment. More importantly, however, electronic prescriptions were viewed as an element of the association of general practitioners' ongoing programme on quality assurance (Pedersen, 1996). Electronic prescriptions allow automatic cross-checking to be performed (for instance, that all fields are filled in properly). The general practitioners were also attracted by the prospects of getting access to the pharmacies' drug item list. This list is provided to the pharmacies by their provider of drugs through the pharmacies' application supplier (NAF-Data, 1994). The list contains information useful also for the general practitioners, for instance, about price and synonymous drugs. It is updated on a monthly basis. As we will spell out in more detail in Section 5.9, this list turned out to become the source of much controversy.

A key challenge in the prescription project was to find a way to align the interests of the involved actors, most importantly the pharmacies and the general practitioners. According to actor network theory, this takes place by translating these interests and inscribing them into a material (Section 2). This drug item list play the role of such a material. Today, the list of drugs accessible to the general practitioners medical record system is either manually entered and updated or is provided through the vendors of medical records systems at a substantial cost. 


\subsection{The irreversibility of EDIFACT}

The activities concerning prescription were more formally organized as a pre-project in the autumn 1992, lasting for 3 months. It built upon the work done by KITH for Statskonsult (KITH, 1992) and aimed at working out a message specification and an implementation guide. The pre-project was financed by NAF-Data, the provider of applications for the pharmacies. Only three actors with immediate interests were represented: the association of general practitioners, the association of pharmacies and KITH (which was delegated the responsibility for coordinating Norwegian efforts).

The choice of a standardization model was not given from the outset. The general Zeitgeist, however, was that of working out as universal and open standards as possible as explained earlier for lab communication (Sections 5.1 and 5.2). Adopting EDIFACT as the basis for electronic prescriptions seemed inevitable even though alternatives were proposed. These alternatives inscribe quite different interests and delegate completely different roles and competencies to involved actors, especially the EDIFACT mafia. We present two of these alternatives that did not have strong enough inscriptions to work against the irreversibility of the EDIFACT actor-network.

Kleven (1992), a representative of one of the vendors of electronic medical record systems (Profdoc), suggested early on that one should use barcodes instead of electronic messages. This inscribes a scenario where the general practitioners, using a special printer, produce a barcode tag which they stick on to the paper prescription which the pharmacies read using a barcode reader. This solution is dramatically simpler that an EDIFACT solution: it needs no coordination with international standardization bodies, it reduces the number of involved actors to a minimum and it relies on well-known, mature technology only. However, every general practitioner needs a barcode printer. The barcode solution, it seems, was never considered in detail despite the fact that a similar idea had been experimented with in Sweden.

Another alternative to EDIFACT was suggested by the health insurance authorities. It inscribed a different role for the pharmacies and a different behaviour for the patients. This differences were indeed the very motivation for their suggestion as it supported their economical interests. The health insurance authorities proposed an architecture where prescriptions were stored in a data base instead of being transmitted directly to the pharmacies. The important behaviour which is inscribed in this architecture but not in the one based on pure EDIFACT messages, is that the pharmacies should retrieve the prescriptions only when the patient actually arrives at the pharmacies. This entails that the health insurance authorities no longer would pay for prescriptions which never actually get picked up. According to the health insurance authorities, this represents a substantial loss. The data base solution would also inscribe a different patient behaviour, namely the freedom for the patient to choose herself which pharmacy to visit to get the drugs. This is particularly important for reiterated prescriptions.

Despite several alternatives, the prescription project never seriously considered deviating from an EDIFACT message based solution in line with predominant conceptions on politically correct standardization strategies. The project was effectively enrolled in the network of the EDIFACT mafia, where solutions not being in close correspondence with their ideology are rarely implemented.

Still, in many respects the adoption of EDIFACT was coincidental. It was partly a result of the fact that no one had a clear conception of the dramatic increase in complexity involved 
in the EDIFACT actor-network (Section 5.3) and partly that a window of opportunity was opened to promote the Norwegian standardization efforts internationally.

There were essentially three alternatives for a basis of the prescription message considered by the pre-project: (i) the EDIFACT message for exchange of orders, with the name ORDERS, which seemed appropriate as a prescription might be viewed as a kind of order; (ii) an EDIFACT message for prescriptions developed in Denmark, but without being approved by any standardization body; or (iii) to develop a new message. Each of these alternatives inscribe different programs of action for different actors. Alternative (i), for instance, entails that the project gets aligned with the revisions of the ORDERS message. As ORDERS is used in virtually all sectors, this alternative forces revisions of ORDERS stemming from, say, manufacturing, to have implications on transmission of prescriptions in Norway. Through the standardization bodies, Norwegian authorities are obliged to keep up with the latest versions.

The pre-project led by KITH did not decide initially whether to base prescriptions on an existing EDIFACT message or to work out one themselves. Only after the pre-project had started did one become aware of an effort within the message design group devoted to health care within the EDIFACT standardization body at the European level which was looking at prescriptions. A Norwegian (Ellen Brox) became the leader of this group. She was well acquainted with the work of KITH. As international standardization activities concerning prescriptions are modest, she suggested for the EDIFACT group that the message specification developed by KITH should become the basis of a new, international EDIFACT standard for prescriptions. During the autumn of 1992 this was submitted as a so-called 'request for new message' to EDIFACT under the name MEDPRE. It received the so-called status 0 on 1st of March 1993, less than half a year after KITH worked out the initial specification. Soon afterwards, KITH worked out an implementation guide for MEDPRE status 0 for use in Norway (KITH, 1993). The fact that the results of the pre-project so quickly-and surprisingly-gave rise to an international standard, was decisive for the so-far unresolved issue over the three alternatives mentioned above. Among these the last one was adopted, that is, to use MEDPRE, their 'own' message, in the next phase of the project.

The results from the pre-project, (KITH, 1992) together with the implementation guide (KITH, 1993), were circulated to the participants to those involved in the Norwegian efforts for commenting before proceeding with the main project. Reactions varied greatly. The comments from the vendors of electronic medical record systems were particularly important as they were vital to enrol to make an integration of electronic prescriptions and the general practitioners' existing systems feasible. The two largest vendors expressed quite different attitudes.

One (Infodoc) embraced the idea. As they already had some experience with similar work in Sweden on electronic prescriptions, they were favourable. They expected to be able to integrate a prescription module with their medical record system relatively quickly thus giving them a leading edge on competitors. The other principal vendor of medical record systems (Profdoc), however, was quite hostile in their comments (Profdoc, 1993). Their comments were questioning the very idea of electronic transmission of prescriptions. They demanded that the scenarios should be spelled out in more detail in order to make the usefulness more visible. This appeal for a delay may be seen as a translation of their primary interest of opposing the project. They furthermore maintained that among their user group of general practitioners there was only modest interest for electronic prescriptions. This vendor also pointed out the alternative based on barcodes which 'died' so quietly at the 
outset of the project (ibid.). The way the objections of Profdoc were neglected indicates the extent to which the EDIFACT mafia was able to function as a gatekeeper in defining the problem as strictly one of standardization of messages.

\subsection{Peaceful life outside the network}

The limits to where EDIFACT should be used were continuously negotiated despite the agreement on adopting EDIFACT as the overall model. In a different but related case, a system for transmission of so-called 'waiting list data', it was decided not to use EDIFACT (Søtorp \& Wølneberg, 1995). The decision was taken by the project's steering group headed by Bjørn Engum, director at KITH and in charge of the Norwegian standardization activities. This system was to help maintain a central data base containing information about patients waiting for certain kinds of treatment. The system is based on a data format specified without using any standard. It resembles the non-standard solutions for exchange of lab reports. Why, then, did this system resist the EDIFACT network? The primary explanation, as we see it, is that the system was specified and implemented by a rather small group of actors. There was no strong competition among these, neither about the possibility of selling a product to a large market nor acting as gatekeeper. Accordingly, nobody needed to mobilize and enrol standardized technology, like EDIFACT, as an ally to strengthen their position.

\subsection{The message as a material for inscriptions}

An important part of the definition of standardized messages is deciding which data elements should be included in the messages and which should not. These elements are also material for inscriptions.

In the system Dr Fürst's laboratory developed, only basic result data were included. The Health Level 7 message used later on as a prototype, included more information. Reflecting the organization of the health sector in the United States with private financing, economic information was included. Some economic information may be relevant in Norway as well, especially if the message is seen in the context of the overall economic organization of the sector, that is, who is paying for what, who is responsible for quality control and cost containment, which institutions are involved in the payment and what kind of information they need.

Based on use scenarios worked out in the Norwegian lab messages working group during 1991-92, it was concluded that the data set in the Health Level 7 message did not satisfy the needs (KITH, 1991). The message proposal was distributed together with a request for comments. It was, however, decided that economic information should not be included in the first official message standard for reasons of simplicity. This was controversial. The association of pharmacies, for instance, expressed in their comments that the areas of use should be expanded to include information exchange between labs, general practitioners and institutions outside health care such as social insurance and banks.

In some European countries, the patients (through the general practitioners) pay part of the costs of the tests, but not in Norway. For this reason, the price the general practitioners pay for each test is included in the European report message. The general practitioners are invoiced periodically. The price information is important in order to control that the amount they have invoiced is correct. Accordingly, the European standard message include this economic information, and so does the Norwegian subset.

Another open issue was whether the information in a lab order should be included in the result message as well. Usually the result is returned to the ordering physician knowing the 
order specification already. Accordingly, in most cases the order information would be unnecessary. In some situations, however, the result is returned to another general practitioner than the ordering one. This is the case in ambulatory care, where the general practitioner visiting the patient orders a test while the result should be returned to the patient's ordinary general practitioner. In hospitals the ordering general practitioner may have left work and a new one has taken over the responsibility for the patient when the result arrives. In these cases, the result should include the order information as well. If this information is not available, the general practitioner may try to guess (which in many cases would work pretty well), or call the lab and ask them.

The arguments against including the order information are the increasing complexity and size of the messages and message specifications it leads to. One proposal put forth was to send the order as a separate message when needed. This solution needed a reference in the result message to its corresponding order message to avoid confusion. Such references, however, are not a part of EDIFACT as it is used. Technically, it would be very simple to find a working solution. The problem was that it would not follow the 'rules of the game' of defining EDIFACT messages. It worked against deeply inscribed practises of specific ways to use EDIFACT. Accordingly it was ruled out. It was instead decided that the order information could be included in the result message.

These examples illustrate that the inclusion or not of a data element in a standard is an negotiation over which programs of action should or should not be inscribed into the standard. In these negotiations, EDIFACT acts as a powerful actor in the sense that most alternatives are close to the intended and customary way of using EDIFACT.

\subsection{Accumulating the strength of an inscription}

In Section 2 we explained how, according to actor network theory, inscriptions have to be linked to larger actor-networks in order to give them sufficient strength. Exactly what it takes to make an inscription strong enough is not possible to know beforehand, it is a question of practical trial and error. A program of action is inscribed into an increasingly larger actornetwork until the necessary strength is reached. This aspect of actor network theory is nicely illustrated, we believe, by the attempts presented below to inscribe a desired behaviour of general practitioners into the definition of the semantics of one single data element in the prescription message. The question, then, is how to accumulate enough strength for this inscription to actually enforce the desired behaviour of general practitioners. Most examples presented above in a similar way illustrate how EDIFACT inscriptions have accumulated its considerable strength.

A principal reason for the interest in prescriptions from the point of view of the pharmacies was the prospect of improved logistics by integrating the existing electronic ordering of drugs from the drug depot (Norwegian: Norsk Medisinal Depot) (Statskonsult, 1992; KITH, 1993). To exploit the economically interesting possibilities of establishing this kind of justin-time distribution scheme, there had to be a way for the pharmacies to uniquely identify a prescribed drug with the drug which subsequently was ordered from the drug depot. In the electronic ordering of drugs from the drug depot, the pharmacies made use of an existing drug list with a coding scheme for drug identifiers as a six digit article number ${ }^{8}$. This drug list was updated and maintained by the drug depot.

\footnotetext{
${ }^{8}$ Reaching agreement on article numbers has been an important and challenging part of the establishment of EDIFACT networks in several business sectors.
} 
The pharmacies' interests for improved logistics was accordingly translated into a proposal to include this six digit drug identifier into the electronic prescription message. This way of inscribing their interests into the semantics of one data element in the message was proposed by the representative of the pharmacies early in the pre-project (KITH, 1992)9.

No one seems to have objected to this proposal from the pharmacies despite (or may be because of) the fact that the scenario of use which was inscribed was not spelled out in any detail. In particular, the pre-project did not spell out exactly how the general practitioners should provide this drug identification number when making a prescription. The general practitioners do not make any use of this number. They identify drugs by their type or brand names, not their identification number. It is not feasible to increase the workload of general practitioners by demanding that they provide the identifier manually. In that case, electronic transmission would require more work than the paper prescriptions and the general practitioners would have no incentives to change.

Rather than working out a detailed program of action, the representative from the general practitioners' associations suggested that this somehow could be solved if the general practitioners were granted access to the list of drug identifiers the pharmacies had, the list maintained by the drug depot. Gaining access to this list was appealing to the general practitioners for two reasons. Besides the drug identifiers, the list contains other information useful for the general practitioners such as prices and synonymous drugs. The fact that the list is continuously updated was also considered favourable. When the pre-project ended in 1992, what remained was to translate the general practitioners' interests in accessing the drug list into a suitable (but unspecified) inscription and align this with the already agreed upon inscriptions in the prescription message. In actor network theory terms, the inscription which demanded that general practitioners provide the drug identifier was to be strengthened by aligning it with a larger (but unknown) actor-network inscribing access to the drug list for general practitioners.

The proposals from the pre-project (KITH, 1992) were circulated for comments. Profdoc, the sceptical vendor of electronic medical record systems (Section 5.6), was also critical to how the issue of drug identification numbers should be solved (Profdoc, 1993). The solution Profdoc suggested was to extract the identification number from another source, the so-called "Common Catalogue" (Norwegian: Felleskatalogen) instead of the pharmacies' drug list. The "Common Catalogue" is a paper based catalogue which all general practitioners have. It contains information about all registered drugs in Norway including their identification number. In addition, it contains information about treatment of acute poisoning, drugs that interfere each other, and a register over drug producers and pharmacies in Norway. The catalogue is printed once a year, while additions regarding new or obsolete drugs are printed and distributed continuously. The "Common Catalogue" is produced by a publisher (Fabritius) and was recently also available electronically in the form of a CD-ROM. This solution based on the "Common Catalogue" delegates a very different set of roles to the involved actors. The required integration work between the electronic medical record system and the prescription module would now involve the publisher but neither the pharmacies nor the

\footnotetext{
${ }^{9}$ This should not be taken to imply that the pharmacies had their ways in every respect. At the same meeting the pharmacies also suggested including a data segment for bonus arrangements which would have substantially improved their reporting routines the health insurance authorities. This suggestion was declined, mainly for reasons of simplicity (KITH, 1992).
} 
drug depot. Besides simply pointing out a, technically speaking, perfectly feasible alternative to a solution based on the drug list from the pharmacies, Profdoc also had a more selfcentred interest in promoting it. During the period after the pre-project was completed, Profdoc had a series of meetings with the publisher of the "Common Catalogue". Profdoc explored the possibility, independently of the prescription project, to integrate their medical record system with the "Common Catalogue". They had never taken pro-active part in the prescription project (Section 5.6). When the issue of drug identification number surfaced, they apparently seized the opportunity of trying to design a solution delegating a role for themselves and their allies in the prescription project.

The alternative suggested by Profdoc was not pursued in the main project. Instead, the project continued to work on how to make the drug list available. This soon turned out to be a lot more complicated than they imagined. The heart of the matter was that the list belonged to an actor outside the project, namely the drug depot. As the list contained information which was confidential, for instance about profit margins on pharmaceutical products, the drug depot had commercial interests in it and refused to hand it over free of charge. Hence, the attempts to accumulate strength for the inscriptions demanding that general practitioners provide the drug identifier were faced with serious, unforeseen problems. It was necessary to translate the commercial interests of the drug depot, a non-project actor, into an inscription. This would involve inscribing roles and obligations for (at least) the following issues: how to obtain the list from the drug depot, how to 'wash' the list to make it appropriate for use for general practitioners, who should do-and pay for-the work. The fact that the participants in the project had to finance their activities themselves, made negotiations difficult. The problems with working out an agreement with the drug depot dragged on. In a coordination meeting in January 1994 it was stated that an agreement was to be reached.

Late in 1995, the testing of the system for electronic transmission of prescriptions started at a pilot site (one general practitioner and one pharmacy). In this first version of the system, drugs are identified by their ordinary brand names. Employees at the pharmacy will map this name to its identification number manually. When the name is incomplete or misspelled, as it is assumed quite often will be the case, they will call the general practitioner by telephone. This version will not be used for reiterated prescriptions either.

Due to the European Economical Area treaty, the earlier monopoly status of the drug depot has been dismantled as of 1st of January 1995. This paved the road for several distributors of drugs to pharmacies beside the drug depot. Each would have their own drug identification number scheme as no 'global' identification coding scheme exists. This makes the drug depot's earlier situation a lot more vulnerable. To the project leader, the drug depot has stated that they now are willing to give general practitioners free access to their drug list (Yang, 1995). During 1996, the provider of applications for the pharmacies, NAF-Data, has been setting up a data base for all distributors of drugs in Norway including the drug depot. This data base is intended to be made accessible to the general practitioners. It has been decided that a new institution will be established and delegated the responsibility for giving each drug its unique identification number.

\section{DISCUSSION}

\subsection{The emerging picture of information infrastructure standardization}

As pointed out earlier in Sections 3.1 and 3.2, there is a wide variety of information infrastructure standards produced within bodies ISO/CEN, EDIFACT, and Internet Society. 
These standards are on different levels and deals with issues like message definitions, syntax specification, protocols, file type formats, etc. Some standards are general purpose, others are sector specific ones (for instance, health care), and some are global while others are regional. Most of them are currently in-the-making (Section 4). Our study does not provide evidence for drawing far-reaching conclusions regarding all types of information infrastructure standards. We believe, however, that the health care standards we have studied are representative for crucial parts of the standards of the information infrastructures envisioned in for instance the Bangemann report (Bangemann et al., 1994), and that the picture of standardization emerging from our analysis contains important features. We will here point out some main characteristics.

The primary characteristics of standards is that they are not neutral, technical specifications but large actor-networks including systems architectures, message definitions, individual data elements, standardization bodies, existing implementations of the technology being included in a standard, users and user organizations, software vendors, text books and specifications. Programs of action are inscribed into every element of such networks. To reach agreement and succeed in the implementation of a standard, its whole actor-network must be aligned.

The experiences from standardization of information exchange within health care indicate that the actor-networks constituted by standards easily grow unmanageably complex. A striking feature is the extent to which the socio-technical problems of establishing an information infrastructure have been underestimated or are unanticipated. The massively dominant approach to date has been met with surprisingly few objections. The heritage from telecommunication standardization and information modelling (Section 5.1) is evident in the thinking and actions of the EDIFACT mafia. It was, for instance, simply 'obvious' that the problem of developing lab messages in Norway should be translated from acquiring practical experience from situations of use in Norway to aligning the specification with perceived European requirements. The EDIFACT mafia had a gatekeeping role which allowed them to define the problem. And their definition of the problem was accepted. Proponents of alternatives (for instance, Profdoc's barcodes) were incapable of marketing their solutions to users. The statement from EDIFACT cited in (Graham et al., 1996, p.10, emphasis added) illustrates how problems are down-played and benefits are exaggerated: "It should be understood that the benefits of having a single international standard outweigh the drawbacks of the occasional compromise".

The belief in universal solutions, combined with the blindness to the intricate links and interactions between technical and non-technical elements of the actor-networks, creates standards of complexity so that their development proceeds very slowly and makes them close to impossible to implement. If they are implemented, however, the size and complexity of the actor-networks makes them rather irreversible and irresistible as their inscriptions are strong. Our empirical material is limited in its documentation of whether inscribed programs of action are really followed by the users. We think this is generally true as individual users cannot decide how to use networking technologies on their own, it has to be agreed upon by all communicating partners.

The diffusion, in line with (Graham et al., 1996), has been very slow. The non-standardized lab message systems developed and adopted by users in the period 1987 to 1992 are still in use although their further diffusion has stopped. The installations of systems based on standardized lab messages seem to be used as described by the scenarios worked out as part of the standardization work. Similarly, the EDIFACT messages implemented adhere to the 
practice inscribed into the actor-network constituting EDIFACT technology. There is no implementations of the standards based on re-interpretations of some of the design assumptions. Dr Fürst's lab consider implementing a system providing services beyond what can be offered by a standardized one as being too difficult at the moment. This would require cooperation with other actors, and establishing such an arrangement is too difficult as it is based on an anti-program compared to that inscribed into the standards.

\subsection{Micro actors in a macro world}

Standardization usually takes place at international levels. It is a world of large companies (telecommunication operators and manufacturers), international standardization bodies and political institutions like the European Union, national governments and ministries and the United Nations. The actor-networks are difficult to grasp, control and change, and alignment of one standard with an existing actor-network is very slow. Controlling the standardization process and its outcome is hard. If anybody has any kind of control, it is the professional standardization people. In our case this means the EDIFACT mafia. It similarly makes the process more open to improvized and opportunistic choices (Ciborra, 1996; Orlikowski, 1996), for instance, the way the drug depot got enrolled in the prescription project as a result of the surprising discovery that their drug list was an important material for inscriptions.

Still, this lack of control gives small actors opportunities to mobilize support for their proposals and having strong influence on the process and its outcomes. In our case, this is illustrated by the influence of Edgar Glück and Fearnley Data concerning the definition of a standardized message for lab information and the development of a health care information infrastructure in Norway. and Euclides' influence on the work in CEN (Section 5.2). In both cases, the small actors' power was the result of, first, their alliances with existing, technology (Fearnley Data's implementation of the EDIFACT message and the Euclides system respectively), secondly, alliances with non-technological actors involved in the standardization work (KITH, Statskonsult and European Medical EDI in Edgar Glück's case and key people in CEN and the Commission of the European Community in Euclides' case).

\subsection{Beyond actor network theory}

We have so-far embraced actor network theory. Not all aspects of our case fit well with the theory, at least not the minimalistic version we have presented so far. In Latour's example illustrating the concept of inscriptions, the processes is driven and controlled by a manager having a clear intention, consciously experimenting until the program of action is imposed on the hotel guests. Inscriptions are different means of enforcing the same scenario. For instance, the sign at the door and the knob on the key are two alternative inscriptions with the same, well-defined scenario in mind, namely to get the guests to leave their keys at the desk. The hotel manager, in Latour's pedagogic example, combines and tests these inscriptions in a goal-directed manner. This example fits well into the kind of 'managerialism' (or centred, privileged view) which actor network theory has been accused of (Haraway, 1988; Law, 1994). In several of our examples, however, this intentional behaviour is difficult to find. Our case illustrates that more often than not noone had a clear sense of the complexity of the actor-network. As a result of this non-transparency, there were a number of unintended consequences. The manner in which end-user input and practical experience was down-played as a result of aligning lab communication with EDIFACT illustrates this. A related point is that scenarios may inscribe rather vague behaviour rather than detailed programs of action of the kind illustrated by Latour's hotel key example. The scenarios are 
only spelled out as one goes along, constantly improvizing and open to surprises. The problem of making the drug identification numbers available to general practitioners illustrates this well. The actors started out with very vague scenarios in the beginning relying on later adjustments and elaborations. Not all scenarios are made explicit. The kind of use scenarios captured by user requirement documents are typically only implicit about use scenarios. In the standardization efforts we have presented, however, use scenarios are attempted to be made explicit by employing the standardization methodology of the health care committee of CEN (TC 251) document which stresses explicit use scenarios.

Other scholars have made related observations. Bowker et al. (1995) argue that there are always several, alternative actor-networks, never only one. Berg's (1997) notion of localization of rationale also frames this process of stumbling, negotiating and refining the scenarios as one goes along. Ciborra's (1996) notion of 'drifting' and Orlikowski's (1996) notion of 'improvization' similarly points in the direction of unanticipated consequence, stumbling and opportunistic choices. Although never thematized as such, Hughes (1983) account of the development of an infrastructure for electricity contains numerous examples of the same ${ }^{10}$.

\subsection{On the strength of an inscription}

Granted that technological artefacts never fully determine patterns of use, the issue is really to what extent a specific artefact in a given context inscribes a certain behaviour. Analytically viewed, the strength of an inscription relies on three aspects: the size and complexity of the surrounding actor-network which is linked to the inscription, the degree to which it is aligned with this surrounding actor-network and the strength of the inscription on its own.

The notion of the strength of an inscription offers a different handle on grand, at times dogmatic, issues such as 'empowerment', 'politics' of artefacts, or the debate over technological vs. social determinism. Rather than, say, inquiring whether information systems have or have not 'politics' on a fairly general basis (Winner, 1993; Woolgar, 1991a, b), the interesting question-which a notion like the strength of an inscription helps tease out-is to describe the extent to which inscriptions in a given case actually succeed in disciplining use ${ }^{11}$. From this point of view, to talk about the 'politics' of an artefact is nothing but a convenient shorthand for a situation where the strength of the inscriptions of the artefact in question is very strong.

When analysing large technical systems like information infrastructures, it is difficult to keep track of the contributions from the various components, that is, the constraints mediated by the inscriptions of the other components. What we are primarily interested in is what we call 'strong inscriptions'. To illustrate, consider the case of the ongoing process of developing Internet standards extending the WorldWideWeb. The inscribed programs of actions are linked to inscriptions in other Internet standards, which are linked to Internet's origin as a Darpa project, which in turn is linked to the United States Department of Defence. The 'military-industrial complex' has, in principle, inscribed behaviour in WorldWideWeb

\footnotetext{
${ }^{10}$ One might ask whether this lack of clear and stable scenarios is intrinsic to the development of large technical systems like an information infrastructure-is it possible to have a coherent, overall conception of something that big?

"This is in line with the argument of Berg (1997)
} 
standards. Leaning on the notion of the strength of inscriptions, we would maintain that (for most purposes) these inscriptions are too weak to be interesting.

\section{CONCLUSION}

Information infrastructures are complex and so is information infrastructure standardization. This not a new and original statement, neither one that is difficult to argue. Nor is it our main point. Rather, we seek to illustrate how standards and standardization of information infrastructure can be conceptualized as actor-networks, how standards are means to stabilize large actor-networks. This enables us to show how all elements of a standard (viewed as an actor-network) inscribe use behaviour. Here the notion of an inscription may help us in dealing with the complexity of information infrastructures and develop more appropriate standards.

It is no exaggeration to say that the difficulties of establishing an information infrastructure have been grossly underestimated by those involved. Coupled with unrealistically high expectations about future benefits, this has created a lot of frustration. What is lacking is a better developed sense of the nature of these socio-technical difficulties together with suitable concepts for framing them. The notion of inscriptions seems to us to be a promising vehicle for achieving this. It helps unravel the complexity, both technical and non-technical, which needs to be curbed in order to establish a working information infrastructure.

Acknowledgements-We want to thank Marc Berg, Andrew Clement, Bo Dahlbom, Joan Greenbaum, Morten Hatling, Mikael Hård, Mona-Lise Pedersen, Lucy Suchman and Kari Thoresen for valuable comments on earlier drafts of the paper. The anonymous referees also provided constructive comments.

\section{REFERENCES}

Abbate, J. (1994). The Internet challenge: conflict and compromise in computer network. In J. Summerton (Ed.), Changing large technical systems (pp. 193-210). Westview Press.

Akrich, M. (1992). The de-scription of technical objects. In W.E. Bijker \& J. Law (Ed.), Shaping technology/building society (pp. 205-224). MIT Press.

Akrich, M. \& Latour, B. (1992). A summary of a convenient vocabulary for the semiotics of human and nonhuman assemblies. In W.E. Bijker \& J. Law (Ed.), Shaping technology/building society (pp. 259-264). MIT Press.

Bangemann, M. et al. (1994). Europe and the global information society. Recommendations for the European Council.

Berg, M. (1997). Rationalizing medical work. Decision support techniques and medical practices. Cambridge, MA: MIT Press.

Boland Jr., R.J., \& Greenberg, R.H. (1992). Method and metaphor in organizational analysis. Accounting, Management and Information Technologies, 2, 117-141.

Bowker, G. \& Star, S.L. (1994). Knowledge and infrastructure in international information management. Problems of classification and coding. In $\mathrm{L}$. Bud-Frierman (Ed.), Information acumen. The understanding and use of knowledge in modern business (pp. 187-213). Routledge.

Bowker, G., Timmermans, S. \& Star, S.L. (1995). Infrastructure and organizational transformation: classifying nurses' work. In W. Orlikowski, G. Walsham, M.R. Jones \& J.I. DeGross (Ed.), Information technology and changes in organizational work (pp. 344-370). Chapman and Hall.

Callon, M. (1991). Techno-economic networks and irreversibility. In J. Law (Ed.), A sociology of monsters. Essays on power, technology and domination (pp. 132-161). Routledge.

Callon, M. (1994). Is science a public good?. Science, Technology and Human Values, 19, $395-424$.

Callon, M. \& Latour, B. (1981). Unscrewing the big Leviathan: how actors macro-structure reality and how sociologists help them to do so. In K. Knorr-Cetina \& A.V. Cicourel (Ed.), Towards an integration of micro- and macrosociologies (pp. 259-276). Routledge and Kegan Paul 
Callon, M. \& Latour, B. (1992). Don't throw the baby out with the bath school! A reply to Collins and Yearley. In A. Pickering (Ed.), Science as practice and culture (pp. 343-368). The University of Chicago Press.

CEN (1991). Minutes and associated papers from 1st CEN TC 251 WG3 Meeting (6.-8.07.91).

CEN (1992). Minutes and associated papers from 5th CEN TC 251 WG3 Meeting; Appendix 5: Report from PT008-Laboratory Messaging - revised set of documents (16-18.10.92).

CEN (1993a). CEN/TC 251/WG 3/PT008/N93-185: Messages for Exchange of Clinical Laboratory Information, First Working Document 1993-10-11 (Red Cover Procedure).

CEN (1993b). CEN/TC 251/WG 3/PT008: EDIFACT Message Implementation Guidelines (October).

CEN (1994a). Medical Informatics. Messages for Exchange of Laboratory Information.

CEN (1994b). Medical Informatics, N94-68. Supporting Document.

Ciborra, C. (1992). Innovation, networks and organizational learning. In C. Antonelli (Ed.), The economics of information network (pp. 91-102). North-Holland.

Ciborra, C. (1996). Introduction: what does groupware mean for the organizations hosting it? In C. Ciborra (Ed.), Groupware and teamwork. Invisible aid or technical hindrance? John Wiley and Sons.

Collins, H. \& Yearley, S. (1992). Epistemological chicken. In A. Pickering (Ed.), Science as practice and culture (pp. 301-326). The University of Chicago Press.

David, P.A. (1987). Some new standards for the economics in the information age. In P. Dasgupta \& P. Stoneman (Ed.), Economic policy and technological performance (pp. 206-239). Cambridge University Press.

Fujimura, J.H. (1992). Crafting science: standardized packages, boundary objects, and "translations". In A. Pickering (Ed.), Science as practice and culture (pp. 168-214). The University of Chicago Press.

Graham, I., Spinardi, G., Williams, R., \& Webster, J. (1995). The dynamics of EDI standards development. Technology Analysis and Strategic Management, 7, 3-20.

Graham, I., Lobet-Maris, C. \& Charles, D. (1996). EDI impact: social and economic impact of electronic data interchange (EDI). TEDIS project $\mathrm{C} 9$, report prepared for the European Commission, http://www.ed.ac.uk/ ehjar 36/tedis.html.

Gustavsen, B. \& Engelstad, P.H. (1990). Creating systems by dialogue-an emergent trend in organization development projects. In G. Bjerknes \& B. Dahlbom (Ed.), Organizational competence and system development. Lund: Studentlitteratur.

Hanseth, O., Monteiro, E. \& Hatling, M. (1996). Developing information infrastructure standards: the tension between standardisation and flexibility. Science Technology and Human Values, 21, 407-426.

Hanseth, O., Thoresen, K., \& Winner, L. (1993). The politics of networking technology in health care. Computer Supported Cooperative Work, 2, 109-130.

Haraway, D. (1988). Situated knowledges: the science question in feminism and the privilege of partial perspective. Feminist Studies, 14, 575-599.

Henderson, A. \& Kyng, M. (1991). There is no place like home: continuing design in use. In J. Greenbaum \& M. Kyng (Ed.), Design at work (pp. 219-241). Lawrence Erlbaum Associates.

Hughes, T.P. (1983). Networks of power. Electrification in Western society 1880-1930. The John Hopkins University Press.

Hughes, T.P. (1987). The evolution of large technical systems. In W.E. Bijker, T.P. Hughes \& T. Pinch (Ed.), The social construction of technological systems (pp. 51-82). MIT Press.

Kahin, B. \& J. Abbate (Eds.). (1995). Standards Policy for Information Infrastructure. MIT Press.

KITH (1991). Comments to the previous implementation guide for the laboratory report message, Nov./Dec.

KITH (1992). Report from the pre-project EDI-based exchange of drug prescription (In Norwegian), Nov.

KITH (1993). Handbook for EDIFACT-based prescription messages, version 1.0 (In Norwegian).

KITH (1994). Information model for laboratory communication-preliminary-Appendix 4: Comments to (CEN 1993a), February.

Klein, H. \& Lyytinen, K.J. (1992). Towards a new understanding of data modelling. In C. Floyd et al. (Ed.), Conference on software development and reality construction (pp. 203-220). Springer-Verlag.

Kleven, V. (1992). Electronic transmission of prescriptions--bar code based (In Norwegian), Note Profdoc.

Kling, R. (1991). Computerization and social transformations. Science, Technology and Human Values, 16, 342 367.

Latour, B. (1987). Science in action. Open University Press.

Latour, B. (1991). Technology is society made durable. In J. Law (Ed.), A sociology of monsters. Essays on power, technology and domination (pp. 103-131). Routledge.

Law, J. (1994). Organizing modernity. Basisl Blackwell.

Lehr, W. (1992). Standardization: understanding the process. Journal of the American Society for Information Science, 43, 550-555. 
MacKenzie, D. (1990). Inventing accuracy. A historical sociology of nuclear missile guidance. MIT Press.

McGarty, T. (1992). Alternative networking architectures: pricing, policy and competition. In B. Kahin (Ed.), Building information infrastructure, McGraw Hill.

Monteiro, E. \& Hanseth, O. (1995). Social shaping of information infrastructure: on being specific about the technology. In W. Orlikowski, G. Walsham, M.R. Jones \& J.I. DeGross (Ed.), Information technology and changes in organisational work (pp. 325-343). Chapman and Hall.

NAF-Data (1994). Requirements specification for implementation of a EDI-module for drug prescription in the pharmacies application (In Norwegian), February.

OECD (1991). Information technology standards: the economic dimension. Paris: Information Computer Communication Policy.

Orlikowski, W.J., \& Robey, D. (1991). Information technology and the structuring of organizations. Information Systems Research, 2, 143-169.

Pedersen, M.-L. (1996). Systems development: and standardisation: two case studies (In Norwegian), Thesis, Department of Informatics, Norwegian University of Science and Technology, Trondheim.

Pfaffenberger, B. (1988). Fetisched objects and humanised nature: towards an anthropology of technology. Man, 23

Profdoc (1993). Comments to functional description (In Norwegian), Profdoc.

RFC (1994). The Internet standards process-revision 2. RFC 1602, IAB and IESG, March.

Rose, M.T. (1992). The future of OSI: a modest prediction. In Proceedings of the Usenix conference.

Sandberg, A. (Ed.) (1979). Computers dividing man and work. Stockholm: Arbeidslivscentrum.

Schmidt, S.K. \& Werle, R. (1992). The development of compatibility standards in telecommunications: conceptual framework and theoretical perspective. In M. Dierkes \& U. Hoffmann (Ed.), New technology at the outset. Social forces in the shaping of technological innovations (pp. 301-326). Campus Verlag.

Smarr, L.L. \& Catlett, C.E. (1992). Life after Internet: making room for new applications. In Building information infrastructure (pp. 144-173). McGraw-Hill.

Star, S.L. \& Ruhleder, K. (1994). Steps towards an ecology of infrastructure: complex problems in design and access for large-scale collaborative systems. In Proceedings of the CSCW' 94 (pp. 253-264).

Statskonsult (1992). EDI transmittal of prescriptions. Final report (In Norwegian), February.

Søtorp, H.U. \& Wølneberg, J. (1995). Inndata til Ventsys-sentralt ventelisteregister. Oslo: Kommuneforlaget AS.

Timmermans, S. \& Berg M. (1997). Standardization in action: achieving universalness and localization in medical protocols. Social Studies of Science.

Trauth, E.M., Derksen, F.E.J.M., \& Mevissen, H.M.J. (1993). The influence of societal factors on the diffusion of electronic data interchange in the Netherlands. IFIP Transactions A, A.24 323-337.

United Nations (1996). Interim report prepared for meeting of experts on data elements and automatic data interchange. UN Economic and Social council, TRADE/WP.4/R.1189.

Webster, J. (1995). Networks of collaboration or conflict? The development of EDI. In R. Williams (Ed.), The social shaping of Interorganizational IT systems and electronic data interchange (pp. 17-41). European Commission. PICT/COST A4.

Winner, L. (1977). Autonomous technology. Technics-out-of-control as a theme in political thought. MIT Press.

Winner, L. (1993). Upon opening the black box and finding it empty: Social constructivism and the philosophy of technology. Science. Technology, and Human Values, 183 362-378.

Williams, R. (1997). Universal solutions or local contingencies: tensions and contradictions in the mutual shaping of technology and work organisation. In I. McLougling, \& D. Mason (Ed.), New perspectives on technology, organisation and innovation, to appear.

Woolgar, S. (1991). The turn to technology in social studies of science. Science, Technology, and Human values, 16 $20-51$.

Woolgar, S. (1991b). Configuring the user: the case of usability trials. In J. Law (Ed.), A sociology of monsters. Essays on power, technology and domination (pp. 57-102). Routledge.

Yang, J. (1995). Interview by M.-L. Pedersen. 